\title{
Cardiac Herniation with Torsion after Right Pneumonectomy
}

Sir,

This presentation illustrates the case of a woman in her forties with right-sided lung cancer [Figure 1] nonsmall cell lung cancer International Union Against Cancer stage III $\mathrm{A}(\mathrm{pT} 4, \mathrm{pN} 0, \mathrm{cM} 0)$.

For preoperative screening, a positron emission tomography/ computed tomography was performed. Subsequently, she was suspected to be rather in stage N2. Consequently, she underwent transpericardial pneumonectomy. After an uneventful surgery, the patient was transferred to the intensive care unit for postoperative monitoring. She was hemodynamically stable and had already been extubated in the operating room.

On postoperative chest X-ray, a mediastinal shift to the operated side as well as a herniation of the heart into the right chest cavity was seen [Figure 2]. While the patient remained

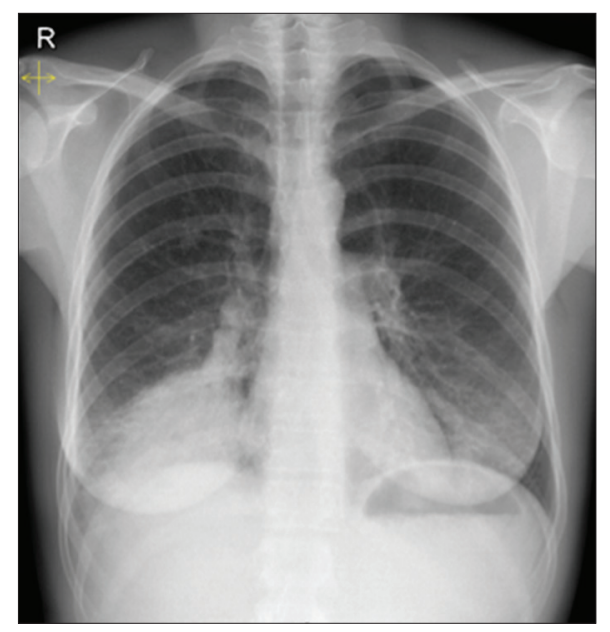

Figure 1: Preoperative chest X-ray

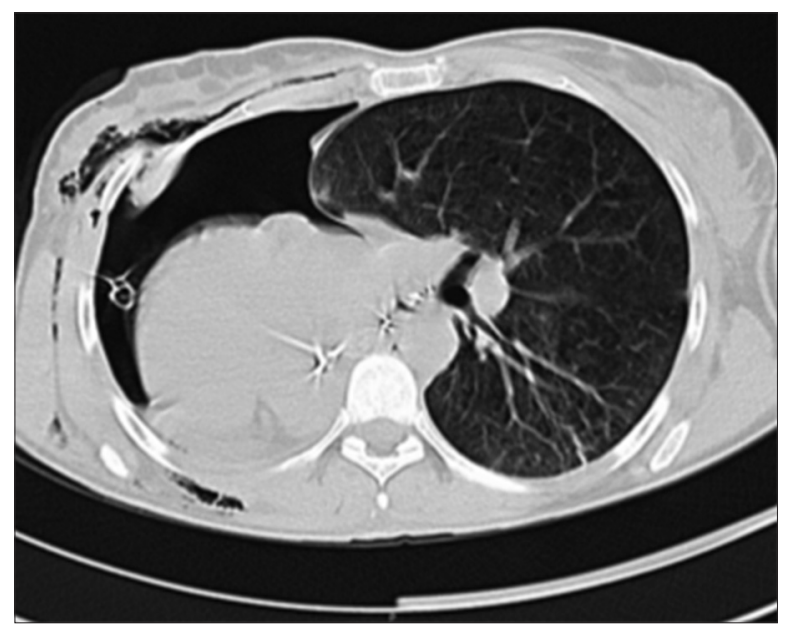

Figure 3: Computed tomography at heart level hemodynamically stable a computed tomography of the chest was performed which confirmed the diagnosis of cardiac herniation and torsion [Figures 3 and 4].

Pneumonectomy carries a high risk of complications, one of which is cardiac herniation. ${ }^{[1]}$ Fixation of the heart in its position in the middle of the mediastinum is dependent on the integrity of the pericardial sac. Stability of the pericardium within the chest results from sternopericardial ligaments and the three point fixation with the diaphragm, superior vena cava (SVC) and inferior vena cava (IVC) where the pericardium joins the adventitia of the vessels.

The surgery related loss of this fixation (SVC, IVC and the ipsilateral pulmonary veins at their pericardial junctions) may

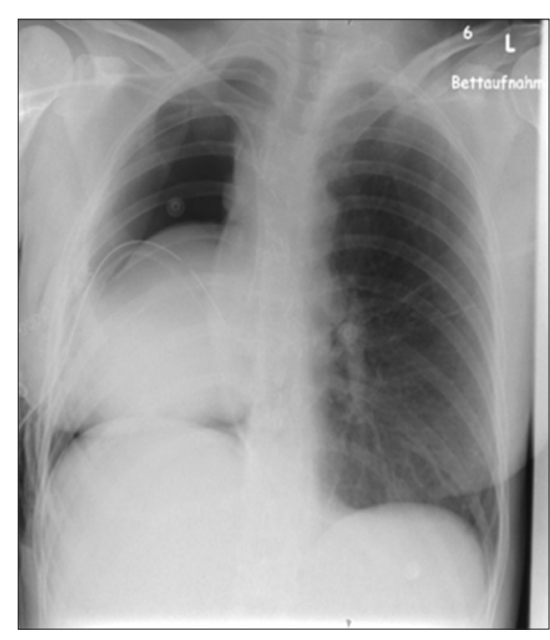

Figure 2: Herniation of the heart into the right chest cavity

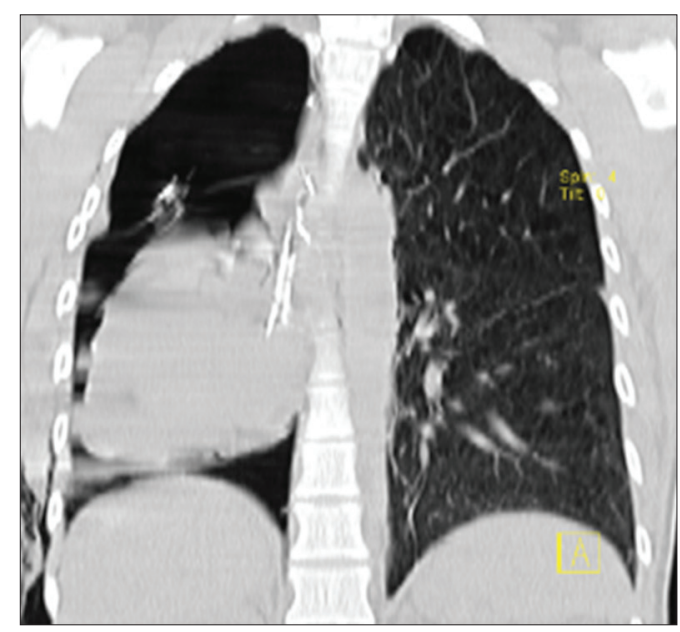

Figure 4: Reconstruction of thoracic slices illustrating the swing around the axis superior vena cava-here with central venous catheter- and inferior vena cava 
enable the heart to slip through the defect of the pericardiotomy and to rotate its tip to the right. ${ }^{[2,3]}$ This displacement may be caused by increased intrathoracic and or abdominal pressures or by increased right hemithorax negative pressure (i.e., improper drainage). ${ }^{[4]}$

The rotation around the axis SVC/IVC may lead to torsion of these large vessels. Accordingly, there is a dramatic reduction in cardiac preload and thus cardiac output.

This critical changes in hemodynamics specify the clinical picture and its urgency. ${ }^{[1,3]}$

Female patient underwent rethoracotomy where the heart was repositioned, and the pericardial defect was closed with a $10 \mathrm{~cm} \times 15 \mathrm{~cm}$ Teflon patch [Figure 5]. She made an uneventful recovery. Four years after pneumonectomy, she remains well and is without relapse of lung cancer.

In debriefing the case, the surgeon self-critically argued that he might rather had closed the pericardial defect with individual button sutures than with continuous suture, as he did.

This rare but life-threatening clinical entity was first described by Bettman and Tannenbaum in 1948. ${ }^{[5]}$ Since then, this clinical emergency has been published numerous times. The clue to early diagnosis is a high index of clinical suspicion according to characteristic situation and pathophysiology as well as the knowledge of the typical radiologic signs. ${ }^{[1,6]}$

It should be highlighted that a hemodynamically unstable patient (which is the usual presentation) under these

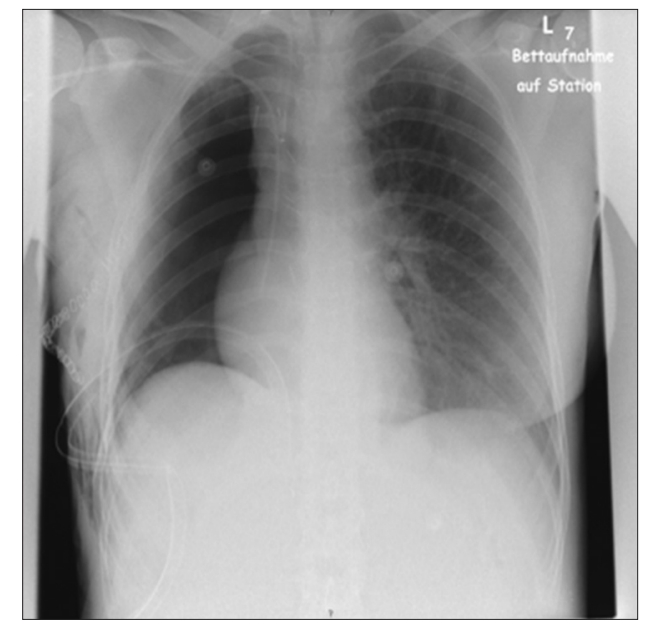

Figure 5: Chest X-ray after repositioning of the heart circumstances demands urgent rethoracotomy and immediate repositioning of the distorted heart. ${ }^{[1,3,6]}$ Otherwise, the mortality is in the range of $50 \%-80 \%{ }^{[1,2,6]}$

The patient consented to publication of her case.

\section{Financial support and sponsorship}

Nil.

\section{Conflicts of interest}

There are no conflicts of interest.

Wolfram Schummer
Anesthesiology and Intensive Care Medicine, Friedrich Schiller
University Jena, Jena, Germany
Address for correspondence: Dr. Wolfram Schummer,
Friedrich Schiller University Jena, Jena, Germany.
E-mail: wolfram.schummer@web.de

\section{RefERENCES}

1. Tschersich HU, Skorapa V, Fleming WH. Acute cardiac herniation following pneumonectomy. Radiology 1976;120:546.

2. Shimizu J, Ishida Y, Hirano Y, Tatsuzawa Y, Kawaura Y, Nozawa A, et al. Cardiac herniation following intrapericardial pneumonectomy with partial pericardiectomy for advanced lung cancer. Ann Thorac Cardiovasc Surg 2003;9:68-72.

3. Holloway B, Mukadam M, Thompson R, Bonser R. Cardiac herniation and lung torsion following heart and lung transplantation. Interact Cardiovasc Thorac Surg 2010;10:1044-6.

4. Ohri SK, Siddiqui AA, Townsend ER. Cardiac torsion after lobectomy with partial pericardectomy. Ann Thorac Surg 1992;53:703-5.

5. Bettman RB, Tannenbaum WJ. Herniation of the heart: Through a pericardial incision. Ann Surg 1948;128:1012-4.

6. Groh J, Sunder-Plassmann L. Heart dislocation following extensive lung resection with partial pericardial resection. Anaesthesist 1987;36:182-4.

This is an open access article distributed under the terms of the Creative Commons Attribution-NonCommercial-ShareAlike 3.0 License, which allows others to remix, tweak, and build upon the work non-commercially, as long as the author is credited and the new creations are licensed under the identical terms.

\begin{tabular}{|l|l|}
\hline \multicolumn{3}{|c|}{ Access this article online } \\
\hline Quick Response Code: & Website: \\
& www.ijccm.org \\
& \\
&
\end{tabular}

How to cite this article: Schummer W. Cardiac herniation with torsion after right pneumonectomy. Indian J Crit Care Med 2017;21:473-4. 